\title{
Triple Threat Trauma: Evidence-Based Mental Health Response for the 2011 Japan Disaster
}

\author{
James M. Shultz, MS, PhD $;{ }^{1}$ Fiona Kelly, $\mathrm{PhD} ;{ }^{2}$ David Forbes, $\mathrm{PhD} ;{ }^{3}$ Helen Verdeli, $\mathrm{PhD} ;{ }^{4}$ \\ Gloria R. Leon, PhD; ${ }^{5}$ Alexa Rosen; ${ }^{6}$ Yuval Neria, $\mathrm{PhD}^{7}$
}

1. Director, Center for Disaster \& Extreme Event Preparedness (DEEP Center), University of Miami Miller School of Medicine, Miami, Florida USA

2. Department of Adult Psychiatry, University College Dublin, Mater Miserlcodiae University Hospital, Dublin Ireland

3. Deputy Director, Australian Centre for Posttraumatic Mental Health (ACPMH), Department of Psychiatry, The University of Melbourne, East Melbourne, Victoria Australia

4. Teachers College and Department of Psychiatry, Columbia University and the New York State Psychiatric Institute, New York USA

5. Department of Psychology, University of Minnesota, Minneapolis, Minnesota USA

6. Research Associate, Center for Disaster \& Extreme Event Preparedness (DEEP Center), University of Miami Miller School of Medicine, Miami, Florida USA

7. Professor of Clinical Psychology, Director, Trauma and PTSD Program, Columbia University, Department of Psychiatry, and the New York State Psychiatric Institute, New York, New York USA

\section{Correspondence:}

James M. Shultz, PhD,

251 174 $4^{\text {th }}$ Street \#2319

Sunny Isles Beach, Florida USA

E-mail: jamesmichaelshultz@gmail.com

doi:10.1017/S1049023X11006364
Background

On March 11, 2011, a Richter Magnitude 9.0 earthquake occurred in the ocean along a seismically-active tectonic plate boundary $120 \mathrm{~km}$ east of Japan's main island, Honshu. The earthquake launched a tsunami of immense magnitude, surging toward the Japanese coastline with limited time to warn coastal residents. As the tsunami crashed ashore, several nuclear power plants were seriously damaged, precipitating a succession of explosions and subsequently, containment structure leaks that sent significant amounts of radioactive material drifting over major population centers and later discharging into the Pacific Ocean.

The triplet of earthquake, tsunami, and radiation releases distinguishes the hazard profile of this event. From a psychosocial perspective, multiple, sequential disaster impacts are known to produce greater psychological distress than a singular exposure. ${ }^{1}$ Therefore, exposure to both natural disaster hazards (earthquake and tsunami) and human-generated radiation hazards expanded the range of psychological stressors experienced by survivors. Large-scale population evacuation ensued for two different reasons, tsunami devastation and radiation threat, as a complex humanitarian crisis emerged.

\section{Optimal Mental Health and Psychosocial Support (MHPS) in Disasters}

Particularly notable was the early recognition by the government of Japan that there would be potent psychological consequences necessitating a multi-faceted MHPS response. ${ }^{2}$ In our view, to create an effective MHPS response, the following elements need to be considered, all based on scientific studies of efficacy and effectiveness: (1) prioritization of mental health needs of disaster survivors and responders; (2) rapid post-impact/pre-deployment guidance for MHPS response based on identification of the salient event-specific, evidence-based, risk factors; (3) early evidence-based MHPS actions, ideally coupled with a "gatekeeper" function to minimize the application of non-empirically-based and/or potentially detrimental activities; (4) on-scene validated mental health assessment leading to early detection of survivors at high-risk for psychopathology; (5) culturally-adapted, evidence-based mental health interventions for survivors with significant distress or psychopathology; and (6) post-disaster surveillance of community mental health with active facilitation of community resilience.

\section{Guiding the 2011 Japan Earthquake MHPS Response with Scientific Evidence}

The potential for continuously improving MHPS response is being realized during the early aftermath of the 2011 Japan Earthquake. As described below, this will become apparent as we examine sequentially the six components that we believe characterize an optimal MHPS response.

\section{Prioritize Mental Health Response}

Within the first days after the disaster, there was recognition of the primacy of psychological consequences and immediate activation of mental health assets. MHPS response was identified as a priority in situation reports issued during the first week post-earthquake. ${ }^{2}$ Moreover, assessments conducted with survivors in 73 evacuation centers highlighted the needs for psychosocial support. By March 25, 2011, 25 Japanese mental health teams had been deployed to the worst-affected areas and on March 28, the Japanese government activated 23 additional psychosocial teams. ${ }^{3}$ The Japanese Red 
Cross Society had 2,369 trained nurses ready to deliver MHPS services, particularly for children.

\section{Guide MHPS Response Based on Psychological Risk Factor}

Assessment

One promising enhancement to infuse scientific evidence into MHPS response is analysis of the psychological risk factors at play in a disaster event. We recently developed a model to perform this function entitled, "Trauma Signature Analysis" (TSIG). ${ }^{4}$ TSIG is based on the notion that risk factors for disaster-related psychological distress and impairment have been documented empirically and can be identified from early disaster situation reports ("sitreps"). Risk factor analysis facilitates post-impact/pre-deployment guidance to tailor MHPS response to the defining features of each disaster.

\section{Trauma Signature of the 2011 Japan Earthquake Exposure to Hazards: Earthquake}

The 2011 Japan Earthquake, at Richter magnitude M9.0, was 100 times stronger than the M7.0 earthquake that devastated Haiti in January 2010. As the strongest earthquake in recorded Japanese history, and the fourth strongest seismic event since 1900, this powerful quake subjected 39.5 million persons (31 percent of the Japanese population) to very strong, severe, or violent "ground-shaking."

The initial M9.0 "mainshock" was succeeded by 262 aftershocks of magnitude 5.0 or stronger within the first week, producing gripping fear in the moment, associated with potent traumatic reminders of the opening salvo. A subsequent M7.4 earthquake occurred just off the coast of Japan, close to the damaged nuclear reactor, on April 7, 2011. Although the earthquake caused minimal structural collapse and injury, the subjective experience of earthquake ground-shaking is known to provoke prolonged and profound fear and anxiety, including fear of death or grievous harm, well-documented risk factors for post-traumatic stress disorder (PTSD) and psychiatric co-morbidities. ${ }^{6}$

\section{Exposure to Hazards: Tsunami}

Despite sophisticated tsunami warning systems in a disastervigilant nation, the geographic location of the quake permitted very little time to warn of the impending onslaught. The University of Tokyo Earthquake Research Institute reported that the tsunami struck coastal areas closest to the epicenter within 10 minutes of the earthquake mainshock. ${ }^{7}$ A sampling of specific exposures in the 2011 Japan tsunami included minimal warning, fleeing the roiling waters, near-drowning experiences, battering injury from flowing debris, witnessing the death of others in the flood waters, destruction of homes, displacement to shelters, and lack of information on substantial numbers of missing persons.

The evidence-based literature from the 2004 Southeast Asia tsunami has elucidated psychological risk factors for tsunami exposure that are applicable to the Japan crisis. ${ }^{8}$ Degree and severity of exposure to the tsunami were strong risk factors for psychopathology. ${ }^{9-12}$ Special populations were identified as having disproportionate psychological consequences in a tsunami disaster, most notably children, ${ }^{11,13}$ women, ${ }^{14}$ the elderly, ${ }^{9}$ individuals with pre-existing mental illness, ${ }^{15}$ and disaster healthcare workers. ${ }^{16,17}$

\section{Exposure to Hazards: Radiation}

No nation compares with Japan in terms of its history of radiation-related mortality, injury, trauma, and multi-generational health effects. In the 2011 Japan disaster, the psychological effect of perceived population exposure to dangerous levels of radiation was amplified as the multi-week crisis was punctuated by reports of fires and explosions; failed attempts to cool the reactors; plumes of radiation; radioactivity burns to nuclear plant personnel; contamination of food and water; and increasing amounts of radiation from the reactor site. Unfortunately, at the time of this editorial, the radiation threat is ongoing.

The adverse psychological effects of nuclear or radiation exposure among civilians have been well documented, providing guidance on expected outcomes following the Japan disaster. According to the Chernobyl Forum, convenened to mark the twentieth anniversary of the incineration of the Chernobyl nuclear reactor, mental health effects were reported to be the most significant public health consequences of the incident. ${ }^{18}$ Distrust of government information, perceived radiation exposure and realistic uncertainty about future health effects are well-known risk factors for psychological distress. ${ }^{19-24}$ Moreover, toxic disasters can lead to stigmatization and discrimination of people and products from contaminated areas. ${ }^{20,25-28}$ Human-generated disasters marked by perceived loss of control, such as radiation incidents, are particularly likely to produce serious psychological consequences. ${ }^{29}$ The prolonged duration of psychological consequences is notable, extending for more than 20 years in the case of the Chernobyl nuclear plant disaster. ${ }^{23,27,30,31}$

\section{Exposure to Loss: Tsunami}

For two weeks following the Japan disaster, numbers of deaths and missing persons increased daily, reaching a plateau in the range of 28,000 during the third week. ${ }^{3}$ Mortality and population-wide bereavement will factor heavily in the trauma signature. ${ }^{4}$ A particularly troubling aspect of the tsunami is the protracted period of time during which persons are missing with no physical evidence of survival or death.

Exposure to Change: Displacement Due to Tsunami and Radiation One of the most profound types of change is sudden and prolonged displacement, documented to have a long-lasting psychological impact on survivors. ${ }^{32-34}$ Two types of event-specific evacuation took place during the Japan disaster. First, the tsunami destruction displaced 550,000 persons who were subsequently living in temporary shelters throughout the affected prefectures four days after the tsunami. ${ }^{2}$ Second, the Japanese government rapidly evacuated more than 175,000 persons living within a $20 \mathrm{~km}$ radius of the incapacitated Fukushima Daiichi nuclear power plant. ${ }^{3}$

\section{TSIG Summary}

These highlights from the TSIG analysis of the 2011 Japan disaster indicate that a multiplicity of psychological risk factors, related to the degree and types of disaster exposures, predict significant and enduring distress and psychopathology in the affected population. Indeed, there now exists a promising window of opportunity to customize MHPS response to the event-specific exposures, rather than relying upon generic approaches that are uninformed by analysis of the unique attributes of this disaster. 


\section{Implement Early MHPS Response Based on Scientific Evidence}

Early psychological intervention is undergoing a phase of major advancement, following a post-9/11 decade of consensus-building ${ }^{35}$ and dissemination of international guidelines. ${ }^{36}$ In 2004 , world experts convened to examine the science behind early psychological support and intervention. Their primary output was a landmark publication describing the five essential elements of early intervention, defined as safety, calming, connectedness, self-efficacy, and hope. ${ }^{35}$ These five principles are known to be psychologically beneficial based on a far-ranging spectrum of scientific evidence and, collectively, they may assist disaster survivors to cope with the stressors and challenges of disasters. Nevertheless, almost no rigorous field evaluations of specific early interventions have been conducted.

Australian researchers have considered how best to package and sequence early- and intermediate-term psychological interventions. These findings may be adaptable to the Japan disaster. In the aftermath of the severe bushfires in Australia in February 2009, an evidence-informed, three-level framework was developed, outlining recommended levels of care underpinned by an education and training agenda. Level 1 was consistent with current models of psychological first aid (PFA), ${ }^{37}$ an approach recommended in international guidelines. ${ }^{38}$ This approach includes the provision of information, comfort, emotional support, and practical support to those exposed to an event, with assistance provided in a step-wise fashion tailored to the person's needs. Psychological first aid does not purport to prevent the future onset of psychiatric disorders, such as PTSD. Instead, its goals are more modest, focusing on decreasing distress and promoting adaptive coping skills in post-disaster environment. ${ }^{39}$

Level 2 care was designed for primary and allied health providers treating survivors with mild to moderate distress, including worry, sadness, insomnia, anger, decreased ability to function at work, school or home, or other psychological issues after the fires that did not warrant formal mental health intervention. A recently developed model called "Skills for Psychological Recovery" (SPR) was identified as appropriate for survivors with this type of ongoing distress. ${ }^{40}$ Finally, Level 3 care focused on the minority of survivors who were likely, over time, to develop a diagnosable mental disorder. Based on international reports following previous disasters, ${ }^{41}$ it was expected that the predominant disorders would be PTSD, depression, complicated grief, anxiety, and substance abuse. An intensive training program was developed for mental health practitioners to equip them to provide evidence-based treatments targeted at these post-disaster psychiatric disorders.

Despite significant progress in the previous decade, early intervention remains at the stage of "evidence-informed" and a robust evidence base is lacking. ${ }^{42}$ For example, the use of psychological first aid has received endorsement from a series of expert panels $35,36,43,44$ and is the Level 1 approach of choice in the Australian three-tier model. ${ }^{38}$ However, it has not been scientifically tested for efficacy in actual disaster field applications. ${ }^{45,46}$

Each major disaster presents opportunities anew for response improvement. The 2011 Japan disaster may provide the chance to conduct an independent field assessment of psychological first aid. The following factors interplay favorably to create this possibility: availability of PFA in the Japanese language, training and endorsement for the PFA approach, early post-disaster psychosocial support, and access to disaster survivors in orderly shelter environments, including segmentation of survivors by exposure (some survivors had radiation threat but no tsunami exposure while others were exposed to both tsunami and radiation hazards). Similarly, the Level 2 intervention (SPR) also awaits field evaluation. In contrast, strong evidence supports the identification and treatment of individuals with post-disaster psychiatric disorders (Level 3), the focus of our proposed components 4 and 5 for optimal MHPS response.

\section{Conduct On-Scene Validated Mental Health Assessments}

Remarkably, across most disasters, a significant proportion of the disaster-exposed population is minimally affected and able to adapt to the adverse circumstances, displaying considerable resilience. ${ }^{47}$ In addition, significant proportions of survivors with initial psychological distress or impairment are anticipated to recover over time either spontaneously or with minimal support. ${ }^{48,49}$ The net result of these processes of resilience and recovery, when taken together, is that only a subset of the population will manifest long-term psychological difficulties or debilitating chronic health problems.

Nevertheless, although affecting a minority of the disasterexposed population, the psychological and physical sequelae of disasters vary by incident and subsume a range of psychiatric and general medical conditions. Disaster survivors may experience combinations of post-traumatic stress disorder (PTSD), depression, generalized anxiety disorder, alcohol and drug abuse, and complicated grief, occurring in tandem with such medical conditions as diabetes, lipid disorders, cardiovascular and respiratory diseases, and skin problems. ${ }^{50}$ Taken together, there may be a significant disaster-related burden of illness.

We therefore believe that every effort should be made to provide on-scene, validated health and mental health assessment of disaster-exposed populations, conducted in the early postdisaster phase, to identify the most vulnerable individuals and to provide them with timely interventions in order to avoid a long-term, chronic course of illness.

Given the prescience of the Japanese response, in which initial medical and psychosocial needs assessments were conducted with sheltered survivors within the first two weeks, the 2011 Japan disaster provides a platform to systematically implement more sophisticated screening and surveillance early in the recovery phase. We advocate for using the best-validated assessment instruments, and carefully analyzing the screening data in a manner that rapidly identifies high-risk survivors and matches them with timely intervention. Careful analysis that examines exposure to disaster-specific psychological risk factors in relation to symptoms of psychopathology will provide the added dividend of advancing the science of disaster behavioral health.

\section{Implement Culturally-Adapted, Evidence-Based Mental \\ Health Interventions}

To round out the comprehensive, multi-component approach, we suggest that persons with diagnosed psychopathology, or clinically-significant distress, be connected to systems of care that apply culturally-adapted, evidence-based mental health interventions. For this component, scientifically-proven treatments exist and ideally, disaster-affected individuals will be provided access. 
For those individuals exposed to a disaster who develop prolonged and impairing symptoms of psychopathology, acceptable, feasible, ecologically valid and effective mental health interventions need to be made available. A number of psychosocial interventions have been evaluated and demonstrated to be efficacious for use with adults and children struggling with the impact of exposure to disaster trauma in communities around the world: Cognitive Processing Therapy (CPT), Interpersonal Psychotherapy (IPT), Prolonged Exposure, Narrative Exposure Therapy, and Trauma-Focused Cognitive Behavioral Therapy have shown effectiveness when delivered by local providers, whose professional background ranges from clinicians to laypersons. ${ }^{51-53}$ These treatments include exposure-based interventions, narrative-based treatments, combinations of both, and interpersonally-focused therapies. It is especially important to provide these interventions in a manner that maximizes accessibility and minimizes stigma.

\section{Conduct Post-disaster Surveillance of Community Mental \\ Health and Facilitate Community Resilience}

The ideal capstone to this sequence would be the ability to maintain long-term surveillance of the disaster-affected

\section{References}

1. Shultz JM, Espinel Z, Galea S, Reissman, DB: Disaster Ecology: Implications for Disaster Psychiatry. In: Ursano, et al., (eds), Textbook of Disaster Psychiatry. Cambridge, UK: Cambridge University Press, 2007, pp 69-96.

2. Office for the Coordination of Humanitarian Assistance: Japan Earthquake and Tsunami, Situation Report 8, March 19,2011. Available at http://www.reliefweb. int/rw/rwb.nsf/db900sid/VDUX-8F4HWW? OpenDocument\&rc=3\&emid= EQ-2011-000028-JPN. Accessed 05 April 2011.

3. Center for Excellence in Disaster Management and Humanitarian Assistance: Japan Earthquake and Tsunami Update - Monday, March 28, 2011. Available at http://www.reliefweb.int/rw/rwb.nsf/db900sid/KKAA-8FE7RA? OpenDocument\&rc=3\&emid=EQ-2011-000028-JPN. Accessed 05 April 2011.

4. Shultz JM, Marcelin LH, Madanes S, et al:: The Trauma Signature: Understanding the Psychological Consequences of the Haiti 2010 Earthquake. Prehosp Disaster Med 2011; 26(3):xxx-xxx.

5. United States Geological Survey. Prompt Assessment of Global Earthquakes for Response) PAGER-M 9.0 - NEAR THE EAST COAST OF HONSHU, JAPAN. Available at http://earthquake.usgs.gov/earthquakes/pager/events/us/ c0001xgp/index.html. Accessed 05 April 2011.

6. Basoglu M, Salcioglu E, Livanou M: Advances in Our Understanding of Earthquake Trauma and Its Treatment: a Self-Help Model of Mental Health Care for Survivors. In: Neria Y, Galea S, Norris FH, (eds), Mental Health and Disasters. Cambridge, UK: Cambridge University Press, 2009, pp 396-418.

7. Center for Excellence in Disaster Management and Humanitarian Assistance: Japan Earthquake and Tsunami Update - Sunday, March 20, 2011. Available at http://www.reliefweb.int/rw/rwb.nsf/db900sid/RMOI-8F6457? OpenDocument\&rc=3\&emid=EQ-2011-000028-JPN. Accessed 05 April 2011.

8. National Center for PTSD: Tsunami and Mental Health: What Can We Expect? Available at http://www.ptsd.va.gov/public/pages/tsunami-mental-health.asp. Accessed 04 April 2011.

9. Carballo M, Heal B, Horbaty G: Impact of the tsunami on psychosocial health and well-being. Int Rev Psychiatry 2006; 18(3):217-223.

10. Hollifield M, Hewage C, Gunawardena CN, et al.: Symptoms and coping in Sri Lanka 20-21 months after the 2004 tsunami. Brit J Psychiatry 2008; 192:39-44.

11. Vijayakumar L, Kannan GK, Daniel SJ: Mental health status in children exposed to tsunami. Int Rev Psychiatry 2006; 18(6):507-513.

12. Wahlström L, Michélsen H, Schulman A, Backheden M: Different types of exposure to the 2004 Tsunami are associated with different levels of psychological distress and posttraumatic stress. J Trauma Stress 2008; 21(5):463-470.

13. Piyasil V, Ketuman P, Plubrukarn R, et al: Post traumatic stress disorder in children after tsunami disaster in Thailand: 2 years follow-up. J Med Assoc Thai 2007; 90(11):2370-2376.

14. MacDonald R: How women were affected by the Tsunami: A perspective from Oxfam. PLoS Med 2005; 2(6):e178.

15. Bhugra D, van Ommeren M: Mental health, psychosocial support and the tsunami. Int Rev Psychiatry 2006; 18(3):213-216. population, documenting both ongoing mental health sequelae and indicators of resilience. At this moment, early experiments are underway to jumpstart community resilience and the postdisaster phase represents the ultimate teachable moment for implementing resiliency programs. ${ }^{54}$ The MHPS response to the 2011 Japan disaster offers great promise for closing the loop and completing the cycle.

\section{Conclusions}

We have used the example of the still-evolving 2011 disaster in Japan to illustrate the potential for an optimal, integrated, evidence-based MHPS response. Based on immediate prioritization of MHPS response (already achieved) and available guidance based on identification of salient psychological risk factors at play (presented here as a TSIG analysis), Japan is primed to implement and field test the most promising evidence-informed early interventions. These include PFA and SPR; validated assessment to identify high-risk survivors; provision of culturally-appropriate, evidence-based mental health interventions for survivors with significant distress or psychopathology; and monitoring the mental health and resilience of the disasteraffected population.

16. Armagan E, Engindeniz Z, Devay AO, et al:: Frequency of post-traumatic stress disorder among relief force workers after the tsunami in Asia: Do rescuers become victims? Prehosp Disast Med 2006; 21(3):168-172.

17. Chan AOM, Yiong Huak C: Emotional impact of 2004 Asian tsunami on Singapore medical relief workers. Int Rev Psychiatry 2004; 2:152-156.

18. Chernobyl Forum: 2003-2005. Chernobyl's legacy: Health, environmental and socioeconomic impacts. Vienna: International Atomic Energy Agency; 2006.

19. Abbott P, Wallace C, Beck, M: Chernobyl: Living with risk and uncertainty. Health Risk Soc 2006; 8(2):105-121.

20. Barnes G, Baxter J, Litva A, Staples B: The social and psychological impact of the chemical contamination incident in Weston Village, UK: A qualitative analysis. Soc Sci Med 2002; 55:2227-2241.

21. Baum A, Gatchel RJ, Schaeffer MA: Emotional, behavioral, and physiological effects of chronic stress at The Mile Island. J Consult Clin Psychol 1983; 51(4):565-572.

22. Perez Foster RM, Goldstein MF: Chernobyl disaster sequelae in recent immigrants to the United States from the Former Soviet Union (FSU). J Immig Health 2007; 9:115-124.

23. Danzer AM, Weisshaar N: The long run consequences of the Chernobyl catastrophe on subjective well-being and mental health in Ukraine. Evidence from two large data sets. Working paper presented at: Annual Conference of the European Association of Labour Economists (EALE), Tallinn, Estonia, 2009.

24. Koscheyev VS, Leon GR, Gourine AV, Gourine VN: The psychosocial aftermath of the Chernobyl disaster in an area of relatively low contamination. Prehosp Disast Med, 12, 41-46.

25. Bromet EJ, Havenaar JM, Guey LT: A 25 year retrospective review of the psychological consequences of the Chernobyl accident. Clin Oncol 2011; xxx-xxx (in press).

26. Dodgen D, Norwood AE, Becker SM, et al:: Social, psychological and behavioral responses to a nuclear detonation in a US city: Implications for health care planning and delivery. Dis Med Pub Health Prep 2011; 5:S54-S64.

27. Greve KW, Bianchini KJ, Doane BM, et al: Psychological evaluation of the emotional effects of a community toxic exposure. J Occup Environ Med 2005; 47:51-59.

28. Petterson J: Perception vs. reality of radiological impact: The Goiania model. Nucl News 1988; 31:84-90.

29. Baum A, Fleming I: Implications of psychological research on stress and technological accidents. Am Psychol 1993; 46(6):665-672.

30. Beehler GP, Baker JA, Falkner K, et al.: A multilevel analysis of long-term psychological distress among Belarusians affected by the Chernobyl disaster. Pub Health 2008; 122:1239-1249.

31. Havenaar JM, Rumyantzeva GM, van den Brink W, et al::Long-term mental health effects of the Chernobyl disaster: An epidemiologic survey in two former soviet regions. Am J Psychiatry 1997; 154:1605-1607. 
32. Fullilove MT: Psychiatric implications of displacement: Contributions from the psychology of place. Am J Psychiatry 1996; 153:1516-1523.

33. Math SB, John JP, Girimaji SC, et al:: Comparative study of psychiatric morbidity among the displaced and non-displaced populations in the Andaman and Nicobar Islands following the Tsunami. Prehosp Disast Med 2008; 23(1):29-34.

34. Van Griensven F, Chakkraband MLS, Thienkrua W, et al: Mental health problems among in tsunami-affected areas in Southern Thailand. JAMA 2006; 296:537-548.

35. Hobfoll SE, Watson P, Bell CC, et al: Five Essential Elements of Immediate and Mid-term Mass Trauma Intervention: Empirical Evidence. Psychiatry 2007; 70:283-315

36. World Health Organization. Inter Agency Standing Committee. IASC Guidelines on Mental health and Psychosocial Support in Emergency Settings. Available at: http://www.who.int/hac/network/interagency/news/mental_health_guidelines/ en/. Accessed 13 September 2010.

37. Brymer MJ, Jacobs AK, Layne CM, et al. (eds), Psychological First Aid: Field Operations Guide. 2d ed. 2006. Available at: www.nctsn.org and www.nctptsd. va.gov. Accessed 04 April 2011.

38. Forbes D, Creamer M, Bisson J, et al: A guide to guidelines for the treatment of PTSD and related conditions. J Trauma Stress 2010; 23(5):537-552.

39. Bryant RA, Litz B: Mental Health Treatments in the Wake of Disaster. In: Neria Y, Galea S, Norris FH (eds), Mental Health and Disasters. Cambridge, UK: Cambridge University Press, 2009, pp 321-335.

40. Berkowitz S, Bryant R, Brymer M, et al. (eds), Skills for Psychological Recovery: Field Operations Guide: Unpublished draft edition, 2009.

41. Norris FH, Friedman M, Watson P: 60,000 disaster victims speak. Part II: Summary and implications of the disaster nental health research. Psychiatry 2002; 65:240-260.

42. Watson P. :Early intervention for trauma-related problems following mass trauma. In: Ursano RJ, Fullerton CS, Weisaeth L, Raphael B, (eds), Textbook of Disaster Psychiatry. Cambridge, England: Cambridge University Press, 2007, pp 121-139.

43. National Institute of Mental Health: Mental Health and Mass Violence: Evidence-based Early Psychological Intervention for Victims/Survivors of Mass Violence: A Workshop to Reach Consensus on Best Practices. Washington, DC: U.S. Government Printing Office, 2002.
44. National Biodefense Science Board: Disaster Mental Health Recommendations: Report of the Disaster Mental Health Subcommittee of the National Biodefense Science Board. Washington, DC, 2008.

45. Litz BT: Early Intervention for Trauma: Where Are We and Where Do We Need to Go? A Commentary. J Trauma Stress 2008; 21(6):503-506.

46. Raphael B, Maguire P: Disaster Mental Health Research, Past, Present, and Future. In: Neria Y, Galea S, Norris FH (eds), Mental Health and Disasters. Cambridge, UK: Cambridge University Press, 2009, pp 7-28.

47. Bonanno GA, Gupta S: Resilience and disaster. In Neria Y, Galea S, Norris F (eds), The Mental Health Consequences of Disasters. New York: Cambridge University Press, 2009, pp 143-160.

48. Neria Y, Besser A, Kipper D, Westphal A: Longitudinal study of posttraumatic stress disorder, depression and generalized anxiety disorder in civilians exposed to war trauma. J Trauma Stress 2010; 23:322-333.

49. Neria Y, Olfson M, Gameroff MJ, et al:: Long term course of probable PTSD after the 9/11 attacks: A study in urban primary care. J Trauma Stress 2010; 23:474-482.

50. Neria Y, Galea S, Norris F: Mental Health Research of Disasters: Current State, Gaps in Knowledge and Future Directions. In Neria Y, Galea S, Norris F (eds), The Mental Health Consequences of Disasters. New York: Cambridge University Press, 2009, pp 594-610.

51. Bolton P, Bass J, Neugebauer R, et al:: Group interpersonal psychotherapy for depression in rural Uganda: A randomized controlled trial. JAMA 2003; 289(23):3117-3124.

52. Verdeli H, Clougherty K, Onyango G, et al.: Group Interpersonal Psychotherapy for depressed youth in IDP camps in Northern Uganda: adaptation and training. Child Adolesc Psychiatr Clin N Am 2008;17(3):605-24, ix.

53. Neuner F, Schauer M, Klaschik C, et al.: A comparison of narrative exposure therapy, supportive counseling, and psychoeducation for treating posttraumatic stress disorder in an african refugee settlement. J Consult Clin Psychol 2004;72(4):579-587.

54. Norris FH, Stevens SP, Pfefferbaum B, et al.: Community resilience as a metaphor, theory, set of capacities, and strategy for disaster readiness. Am J Community Psychol 2008;41(1-2):127-150. 